\title{
STUDI EKSPERIMENTAL PERPINDAHAN KALOR KONVEKSI, PENURUNAN TEKANAN DAN FAKTOR GESEKAN PADA ALAT PENUKAR KALOR MENGGUNAKAN MICRO-FIN TUBE
}

\author{
Ahmad Imam Rifa'i ${ }^{1}$, Budi Kristiawan ${ }^{1}$, Agung Tri Wijayanta ${ }^{1}$ \\ ${ }^{1}$ Teknik Mesin - Universitas Sebelas Maret
}

\begin{tabular}{ll}
\hline Keywords: & Abstract : \\
\hline Convective heat transfer & \multicolumn{1}{c}{ Micro-fin is the popular technique for increasing heat transfer } \\
Pressure drop & performance of the heat exchangers. In this research, the heat transfer \\
Friction factor & coefficient of water inside counter-flow heat exchangers with micro-fin \\
Micro-fin & was investigated by experiment at the Reynolds number (Re) was varied \\
& from 4000-10,000. The results show that the heat transfer coefficient \\
& increase with increasing Reynolds number. Furthermore, effect helical \\
& micro-fin increasing pressure drop and friction factor at turbulent flow \\
& region..
\end{tabular}

\section{PENDAHULUAN}

Double pipe heat exchangers merupakan alat penukar kalor yang umum digunakan dalam proses industry dan apikasi teknik, baik untuk proses pendinginan maupun proses pemanasan. Perpindahan kalor konveksi berperan penting dalam efisiensi alat penukar kalor. Untuk meningkatkan kinerja alat penukar kalor, metode peningkatan perpindahan kalor terdapat 2 kelompok yaitu metode aktif dan metode pasif. Teknik pasif lebih menguntungkan dibandingkan dengan metode aktif, karena tidak memerlukan penambahan energi eksternal (Alam dan $\operatorname{Kim} 2018)$.

Metode pasif yang paling populer adalah dengan menggunakan micro-fin tube (Honda et al. 2005; Ma et al. 2017). Micro-fin biasanya digunakan pada proses kondensasi maupun evaporasi pada alat pendingin udara serta pendingin air (chiller).

Studi eksperimental dalam meningkatkan koefisien perpindahan kalor dengan menggunakan metode pasif yaitu dengan menggunakan twisted tape insert dilakukan oleh (Wijayanta et al. 2018; Yaningsih et al. 2018). Sedangkan Kristiawan dan Kamal, (2016) melakukan studi eksperimental perpindahan kalor konveksi dengan menggunakan kombinasi teknik perpindahan kalor, yaitu dengan menggunakan fluida nano dan twisted tape insert pada alat penukar kalor untuk kondisi heat flux konstan. Hasil penelitian menjukkan bahwa perpindahan kalor konveksi dan faktor kinerja termal meningkat dengan penambahan twisted tape insert serta meningkatnya volume konsentrasi fluida nano. Namun pada penambahan volume konsentrasi meningkatkan viskositas fluida nano yang menyebabkan penurunan tekanan yang lebih tinggi dibandingkan dengan fluida dasar.

Ma et al. (2017) melakukan studi eksperimental perpindahan kalor fasa tunggal pada alat penukar kalor pipa ganda pada kondisi rezim aliran laminer, transien dan turbulen dengan rentang bilangan Reynolds $100-$ 36.000. Pipa dalam menggunakan pipa halus dan micro-fin tube dengan diameter luar 22,48 $\mathrm{mm}$ dan $16,66 \mathrm{~mm}$ dengan fluida kerja yang digunakan adalah campuran air dan ethylene glycol. Hasil penelitian dilaporkan bahwa faktor gesekan micro-fin tube meningkat dengan meningkatnya nilai e/deq. Faktor gesekan pada micro-fin yang berbeda menunjukan trendline yang berbeda. Kondisi tersebut memiliki kesamaan dengan pipa dengan kekasaran equivalent.

Wu et al. (2013) melakukan penelitian secara eksperimental tentang proses kondensasi dengan menggunakan pipa halus dan 5 micro-fin tube dengan diameter luar pipa dalam $5 \mathrm{~mm}$. Refrigerant yang digunakan adalah jenis R22 dan R401A mengalir di dalam pipa dalam, sedangkan air mengalir pada sisi annulus. Hasil penelitian menunjukan bahwa microfin yang memiliki luas permukaan bagian dalam total dari micro-fin yang tinggi memiliki kemampuan yang terbaik dalam perpindahan kalor pada laju aliran massa yang tinggi.

Dengan menggunakan jenis refrigerant yang sama, Li et al. (2017) melakukan eksperimen pada penukar kalor dengan pipa bagian dalam pipa halus dan micro-fin yang memiliki diameter luar 9.52 dan 5 $\mathrm{mm}$. Hasil penelitian dilaporkan bahwa micro-fin tube menghasilkan $1,65 \quad-\quad 2,55$ kali peningkatan perpindahan kalor yang lebih tinggi dibandingkan dengan pipa halus. Peningkatan tersebut disebabkan area permukaan perpindahan efektif pada micro-fin 
tube dan turbulensi aliran yang disebabkan oleh fin pada permukaan bagian dalam pipa dalam.

Celen et al. (2013)melakukan penelitian tentang penurunan tekanan dan faktor gesekan pada pipa halus dan micro-fin tube dengan laju aliran fluida yang berbeda secara eksperimental pada alat penukar kalor pipa ganda horizontal dengan pengaturan aliran bersilang (counter-flow). Fluida panas mengalir pda sisi pipa dalam sendangkan air dingin mengalir pada sisi annulus.

Hasil penelitian di bandingkan dengan korelasi Blasius dan korelasi Petukhov. Hasil eksperimen menunjukan bahwa koefisien perpindahan kalor micro fin tube 2,9 lebih tinggi dibandingkan dengan pipa halus pada rezim aliran turbulen. Meskipun penurunan tekanan pada micro-fin tube 1,7 lebih tinggi dari penurunan tekanan pada pipa halus.

Dastmalchi et al. (2017) melakukan studi numerik perpindahan panas pada pipa halus dan micro-fin tube dengan menggunakan tinggi fin dan helical angle yang berbeda. Fluida kerja yang digunakan adalah oli untuk kondisi batas suhu dinding konstan. Penelitian dilakukan pada kondisi aliran laminer dengan rentang bilangan Reynolds 100 -

1.000. Hasil simulasi menunjukan bahwa peningkatan perpindahan kalor maksimum pada micro-fin $44 \%$ dan faktor gesekan $69 \%$ lebih tinggi dibandingkan dengan korelasi perpindahan kalor dan faktor gesekan pada bilangan Reynolds 1.000.

Dengan dilakukannya penelitian ini dalam bidang akademis diharapkan dapat memberikan ilmu pengetahuan baru tentang teknik pasif khususnya pada micro-fin tube dalam meningkatkan perpindahan kalor konveksi pada alat penukar kalor pipa ganda. Penelitian ini dilakukan untuk menguji pengaruh variasi laju aliran fluida dingin di pipa dalam (inner tube) dari penukar kalor pipa ganda dengan pipa dalam dilengkapi dengan micro-fin terhadap karakteristik perpindahan kalor konveksi penurunan tekanan serta faktor gesekan.

\section{METODOLOGI PENELITIAN}

Diagram skematik eksperimental ditunjukan pada Gambar 1. Setup alat pengujian terdiri dari seksi uji, aliran fluida panas, aliran fluida pendingin, sistem pengukuran serta sistem data akuisisi. Sistem pengaturan aliran pada studi eksperimen ini adalah dengan menggunakan sistem pengaturan aliran bersilang (counter-flow). Material pipa dalam dari seksi uji terbuat dari tembaga dengan diameter luar Do $=6 \mathrm{~mm}$ dengan panjang area perpindahan kalor $\mathrm{L}$ $=414 \mathrm{~mm}$ dengan jumlah fin 64 dan diameter equivalen $\mathrm{deq}=5,26 \mathrm{~mm}$. Diameter dalam dari pipa luar adalah $23 \mathrm{~mm}$. untuk memastikan aliran fluida yang masuk pada seksi uji full developed flow, maka dipasangkan calming section sebelum seksi uji.

Fluida panas (air) dipanaskan dengan menggunakan pemanas listrik dengan daya 1500 watt dan dijaga konstan pada suhu 50oC dengan mengatur potensio pada pengatur suhu (thermocontrol). Sedangkan fluida panas pada seksi uji dialirkan dengan menggunakan pompa magnetik dengan debit aliran dijaga konstan pada aliran 1,58 liter/min. Sedangkan fluida pendingin dialirkan dengan menggunakan pompa micro gear. Debit aliran fluida pendingin divariasikan dengan mengatur rotasi pompa micro gear dengan ketelitian $1 \mathrm{rpm}$. Chiller digunakan untuk menjaga suhu fluida tetap konstan pada suhu $20 \mathrm{oC}$ selama pengujian berlangsung.

Penurunan tekanan sepanjang seksi uji pipa dalam diukur dengan menggunakan digital manometer dengan ketelitian $0.1 \mathrm{kPa}$. Suhu inlet, outlet dan suhu permukaan pipa dalam pada seksi uji diukur dengan menggunakan thermocouple tipe- $\mathrm{K}$ dengan ketelitian $0.1 \mathrm{oC}$ yang terhubung dengan sistem data akuisisi (Adam 4018+) untuk merekam data eksperimen dengan rentang pengambilan data 500 millisecond (ms).

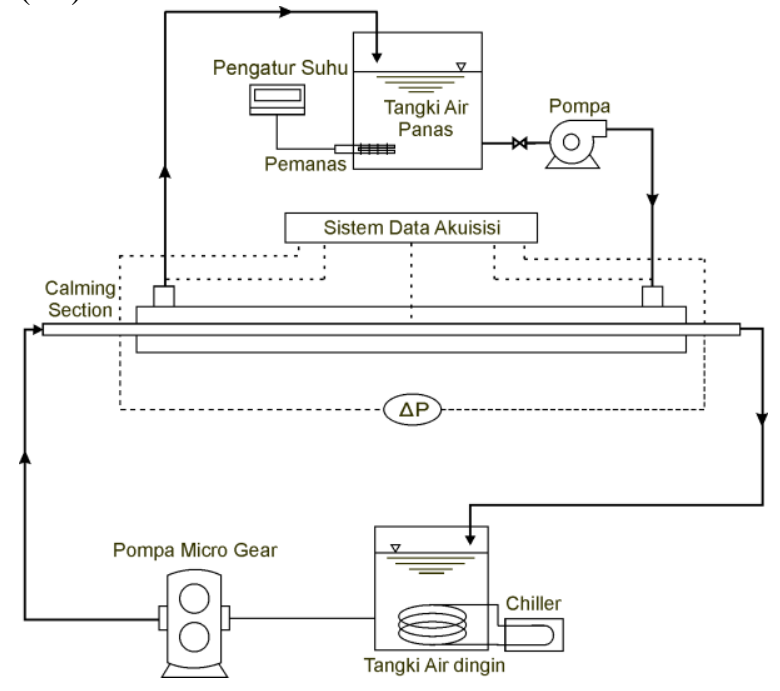

Gambar 1. Diagram Skematik Eksperimental

\section{Reduksi Data}

Dalam studi eksperimen ini, fluida pendingin divariasi pada rentang bilangan Reynolds 4000 10.000 yang digunakan untuk investigasi koefisien perpindahan kalor konveksi dan penurunan tekanan fluida pendingin. Selanjutnya, koefisien perpindahan kalor dan penurunan tekanan fluida pendingin dapat dihitung berdasarkan persamaan :

Laju perpindahan kalor ke air dingin di sisi annulus dapat dinyatakan sebagai berikut :

$$
Q_{h}=\dot{m}_{h} C_{p, h}\left(T_{h, \text { in }}-T_{h, \text { out }}\right)
$$




\section{Mekanika: Majalah Ilmiah Mekanika 11 Volume 18 Nomor 1 Maret 2019}

Laju perpindahan kalor di pipa dalam dihitung dengan :

$$
Q_{c}=\dot{m}_{c} C_{p, c}\left(T_{c, \text { out }}-T_{c, \text { in }}\right)
$$

dimana $Q$ adalah laju perpindahan kalor, $\dot{m}$ laju aliran massa fluida kerja, $C p$ adalah panas jenis fluida, $\Delta T$ perbedaan suhu antara inlet dan outlet seksi uji.

Laju perpindahan kalor rata-rata, $Q_{\text {ave }}$ dihitung berdasarkan laju perpindahan kalor pada sisi air panas dan air dingin sebagai berikut :

$$
Q_{\text {ave }}=\frac{Q_{h}+Q_{c}}{\overline{2}}
$$

Sehingga koefisien perpindahan kalor menyeluruh di pipa dalam, $U_{i}$ dapat tentukan dari :

$$
U_{i}=\frac{Q_{\text {ave }}}{A_{s} \Delta T_{L M T D}}
$$

Dimana $A$ adalah luas permukaan dalam pipa dalam, $\triangle T_{L M T D}$ adalah Logarithmic mean temperature difference.

Koefisien perpindahan kalor air panas pada sisi annulus $\left(h_{o}\right)$ dapat dihitung dengan menggunakan persamaan :

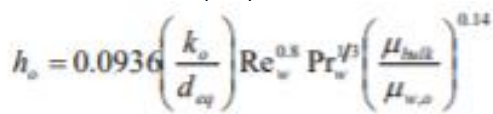

Koefisien perpindahan kalor konveksi di pipa dalam $\left(h_{i}\right)$, dihitung berdasarkan nilai dari persamaan (9) dan (10), maka dapat dinyatakan sebagai :

$$
h_{i}=\frac{1}{\left(\frac{1}{U_{i}}-\frac{d_{0} \ln \left(d_{o} / d_{i}\right)}{2 k_{\mathrm{Gi}}}-\frac{d_{i}}{d_{e} h_{\sigma}}\right)}
$$

Bilangan Nusselt $(\mathrm{Nu})$ rata-rata di pipa dalam dapat dihitung dengan persamaan :

$$
N u_{i}=\frac{h_{i} \cdot d_{i q}}{k_{i}}
$$

Bilangan Reynolds ( $R e$ ) dan bilangan Prandtl (Pr) fluida kerja dapat ditentukan dari persamaan :

$$
\begin{aligned}
& \mathrm{Re}_{i}=\frac{\rho v d_{e i}}{\mu} \\
& \mathrm{Pr}_{i}=\frac{\mu C_{p}}{k}
\end{aligned}
$$

Dimana $\rho$ adalah densitas, $v$ adalah kecepatan aliran fluida, $d_{e q}$ adalah diameter equivalen dalam pipa dalam, $\mu$ adalah viskositas fluida kerja, $C_{p}$ adalah panas jenis, $k$ adalah konduktivitas fluida kerja Penurunan tekanan $(\Delta \mathrm{P})$ sepanjang aliran fluida nano pada pipa bagian dalam ditentukan dari pembacaan digital manometer, sehingga faktor gesekan $(f)$ dapat dihitung menggunakan persamaan :

$$
f=\frac{\Delta P}{\left(\frac{L}{d_{\omega q}}\right)\left(\frac{\rho v^{2}}{2}\right)}
$$

dimana $L$ adalah jarak pengukuran penurunan tekanan di pipa dalam, $d_{e q}$ adalah diameter equivalen micro-fin, $\rho$ adalah densitas fluida nano, $v$ adalah kecepatan rata-rata..

\section{HASIL DAN PEMBAHASAN}

\section{Validasi koefisien perpindahan kalor konveksi}

Karakteristik perpindahan kalor seksi uji divalidasi dengan menggunakan korelasi empirik dari persamaan Dittus-Boelter yang dinyatakan sebagai :

$$
N u=0.023 \operatorname{Re}^{0.8} \operatorname{Pr}^{1 / 3}
$$

Dimana $N u$ adalah bilangan Nusselt, $R e$ adalah bilangan Reynolds, Pr adalah bilangan Prandtl.

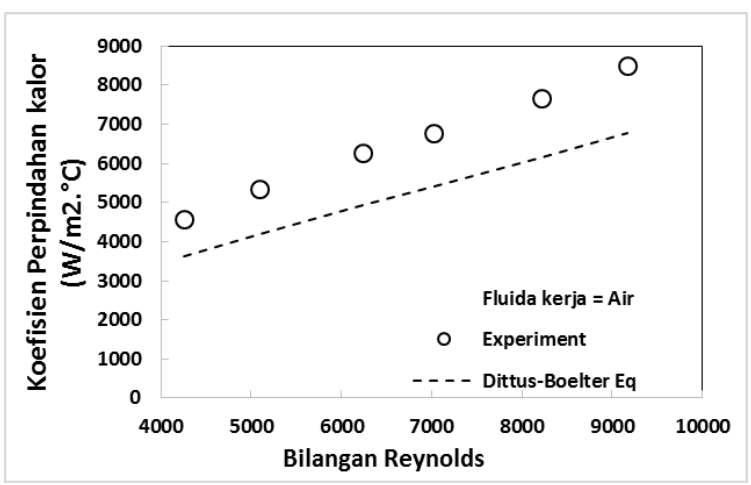

Gambar 2. Validasi koefisien perpindahan kalor dari seksi uji dengan menggunakan fluida kerja air.

Validasi seksi uji ditunjukan pada Gambar 2 dengan menggunakan air sebagai fluida kerja, baik pada sisi annulus dan sisi pipa dalam. Koefisien perpindahan kalor dari hasil eksperimen untuk microfin sesuai dengan hasil prediksi empirik dari korelasi Dittus-Boelter dengan ketidaksesuaian maksimum antara hasil eksperimen dengan korelasi adalah $\pm 12 \%$

\section{Karakteristik Perpindahan Kalor Konveksi}

Hubungan karakteristik perpindahan kalor pipa halus dan micro-fin dengan bilangan Reynolds pada alat penukar kalor pipa ganda dapat dilihat pada gambar 3. Hal tersebut dapat dilihat bahwa karakterisik perpindahan kalor pipa halus dan microfin memiliki tren yang sama, yaitu koefisien perpindahan kalor meningkat seiring dengan bilangan Reynolds. Micro-fin tube memiliki peningkatan perpindahan panas konveksi yang lebih tinggi dibandingkan dengan tabung halus. Hal tersebut dikarenakan micro-fin meningkatkan luas permukaan perpindahan kalor, sehingga dapat menyebabkan peningkatan nilai koefisien perpindahan kalor lebih tinggi dibandingkan dengan pipa halus. Selain itu, efek dari micro-fin menyebabkan turbulensi aliran menjadi lebih tinggi sehingga menghasilkan peningkatan rata- 


\section{Mekanika: Majalah Ilmiah Mekanika 12 Volume 18 Nomor 1 Maret 2019}

rata kecepatan suhu fluida yang seragam yang secara signifikan dapat meningkatkan koefisien perpindahan kalor konveksi dalam pada micro-fin tube Wjayanta et al. (2017) . Peningkatan maksimum adalah 35\% lebih tinggi dibandingkan dengan pipa halus.

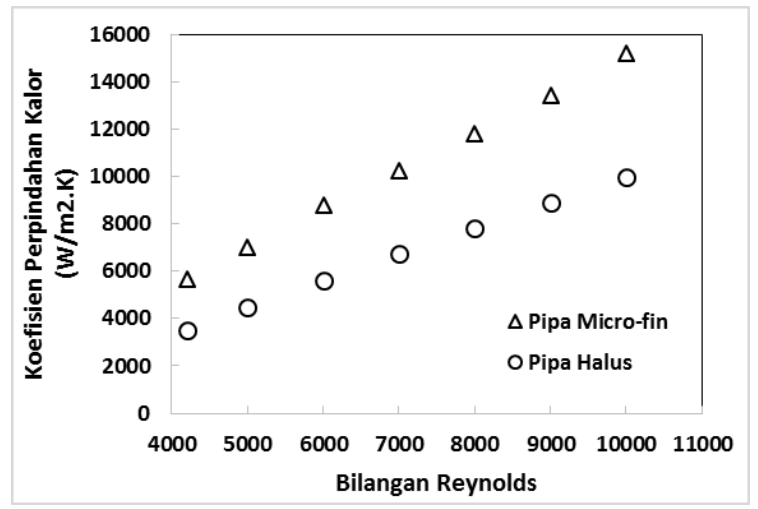

Gambar 3. Hubungan koefisien perpindahan kalor dan bilangan Reynolds

\section{Penurunan tekanan dan Karakteristik Faktor} Gesekan

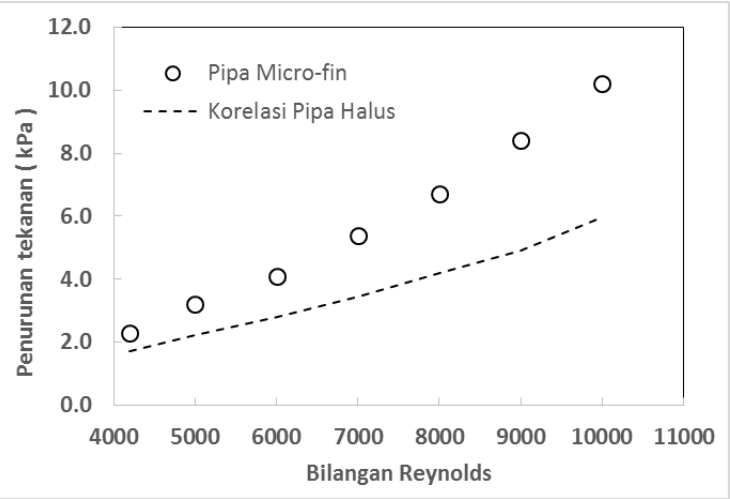

Gambar 4. Hubungan penurunan tekanan pipa microfin dan korelasi Petukhov untuk pipa halus

Hubungan penurunan tekanan pipa halus dan micro-fin tube dengan bilangan Reynolds ditunjukan pada Gambar 4. Hasil penelitian menunjukan bahwa penurunan tekanan meningkat seiring dengan peningkatan bilangan Reynolds. Peningkatan penurunan tekanan tersebut disebabkan oleh efek micro-fin pada permukaan dalam dari pipa dalam sehingga menghasilkan turbulensi aliran dalam pipa yang tinggi dan efek dari fin memberikan tambahan tahanan aliran dari fluida yang mengalir sehingga menimbulkan penurunan tekanan yang lebih besar jika dibandingkan dengan pipa halus. Hal yang serupa juga dilaporkan oleh Celen et al. (2013) dengan fluida kerja campuran antara air dan ethylene glycol. Peningkatan penurunan tekanan tersebut menyebabkan kerugian pada efisiensi alat penukar kalor. Hal tersebbut disebabkan karena meningkatnya daya pemompaan yang meningkat untuk mempertahankan laju aliran yang sama antara tabung halus dan micro-fin tube.

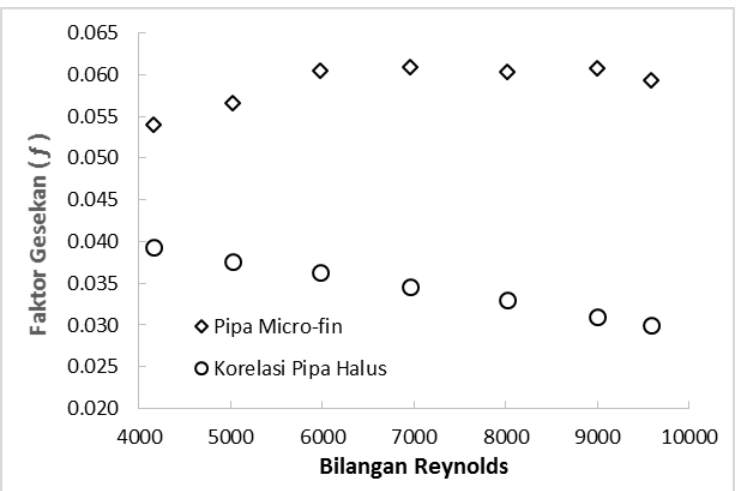

Gambar 5. Hubungan faktor gesekan pipa micro-fin dan korelasi Petukhov untuk pipa halus.

Karakteristik aliran fluida kerja pada penelitian in ditunjukkan pada gambar 5. Dapat dilihat bahwa Faktor gesekan pada pipa halus menurun seiring dengan meningkatnya bilangan Reynolds. Sedangkan micro-fin tube memiliki karakteristik faktor gesekan yang berbeda dengan tabung halus. Hal tersebut dikarenakan efek dari fin menyebabkan tahanan aliran yang lebih tinggi sehingga tekanan dinamis fluida meningkat. Hal tersebut mnyebabkan aliran turbulensi fluida yang tinggi pada kondisi aliran turbulen sehingga faktor gesekan micro-fin tube lebih tinggi dibandingkan dengan faktor gesekan pada pipa halus. Pada kondisi aliran turbulen, trendline faktor gesekan memiliki kesamaan dengan hasil eksperiment yang dilakukan oleh Ma et al., (2017).

\section{KESIMPULAN}

Koefisien perpindahan kalor micro-fin, penurunan tekanan serta faktor gesekan pada alat penukar kalor pipa ganda aliran bersilang telah diteliti secara eksperimental. Maka dapat diambil kesimpulan sebagai berikut :

1. Koefisien perpindahan kalor konveksi meningkat seiring dengan mingkatnya bilangan Reynolds pada kondisi aliran turbulen. Nilai peningkatan perpindahan kalor micro-fin tube lebih tinggi dibandingkan dengan pipa halus.

2. Penurunan tekanan pada pipa micro-fin lebih tinggi dibandingkan dengan pipa halus dan meningkat seiring dengan meningkatnya bilangan Reynolds.

3. Micro-fin menyebabkan turbulensi aliran fluida kerja lebih tinggi dibandingkan pipa halus, sehingga meningkatkan faktor gesekan pada pipa micro-fin untuk kondisi aliran turbulen. 
\begin{tabular}{l|l} 
Mekanika: Majalah Ilmiah Mekanika & 13 \\
Volume 18 Nomor 1 Maret 2019 &
\end{tabular}

\section{UCAPAN TERIMA KASIH}

Penelitian ini didukung oleh LPPM Universitas

Sebelas Maret sesuai dengan Surat Perjanjian

Kontrak Penelitian No. 543/UN27.21/PP/2018, dengan Skim Hibah: Kolaborasi Internasional (KI-

UNS) dengan Research ID : 00250471021232018

\section{DAFTAR NOTASI}

$\mathrm{A}=$ luas permukaan dalam pipa $\left(\mathrm{m}^{2}\right)$

$\mathrm{Cp}=$ panas jenis air dingin $\left(\mathrm{kJ} / \mathrm{kg} .{ }^{\circ} \mathrm{C}\right)$

$\mathrm{d}=$ diameter pipa $(\mathrm{m})$

$\mathrm{f} \quad=$ faktor gesekan

$\mathrm{h}_{\mathrm{i}}=$ koefisien perpindahan panas konveksi ratarata $\left(\mathrm{W} / \mathrm{m}^{2} .{ }^{\circ} \mathrm{C}\right)$

$\mathrm{k}=$ konduktivitas termal $\left(\mathrm{W} / \mathrm{m} .{ }^{\circ} \mathrm{C}\right)$

$\mathrm{Lt}=$ panjang pengukuran penurunan tekanan $\mathrm{di}$ pipa dalam (m)

$\dot{\mathrm{m}}=$ laju aliran massa air panas $(\mathrm{kg} / \mathrm{s})$

$\mathrm{Nu}=$ bilangan Nusselt rata-rata

$\mathrm{Q} \quad=$ laju perpindahan panas di annulus (W)

$\mathrm{Re}=$ bilangan Reynolds

$\mathrm{T}=$ temperatur $\left({ }^{\circ} \mathrm{C}\right)$

$\mathrm{U}=$ koefisien perpindahan kalor overall $\left(\mathrm{W} / \mathrm{m}^{2} .{ }^{\circ} \mathrm{C}\right)$

$\mathrm{v} \quad=$ kecepatan rata-rata $(\mathrm{m} / \mathrm{s})$

\section{Subscripts}

bf = base fluid

$\mathrm{c} \quad=$ cold

eq = equivalent

$\mathrm{h}=$ hot

$\mathrm{i} \quad$ inner tube

in $=$ inlet

$\mathrm{np}=$ nanoparticle

$\mathrm{nf} \quad=$ nanofluid

$\mathrm{o}=$ outer tube

out $=$ outlet

\section{Greek symbol}

$\varphi \quad=$ volume konsentrasi $(\operatorname{vol} \%)$

$\mu \quad=\operatorname{viskositas}(\mathrm{kg} / \mathrm{m} . \mathrm{s})$

$\rho \quad=\operatorname{densitas}\left(\mathrm{kg} / \mathrm{m}^{3}\right)$

$\Delta \mathrm{P} \quad=$ penurunan tekanan $(\mathrm{Pa})$

$\Delta \mathrm{T}_{L M T D}=$ logarithmic mean temperature difference

$\left({ }^{\circ} \mathrm{C}\right)$

\section{DAFTAR PUSTAKA}

[1] T. Alam and M. Kim, "A comprehensive review on single phase heat transfer enhancement techniques in heat exchanger applications," Renewable and Sustainable Energy Reviews, vol. 81, pp. 813-839, 2018.
[2] A. Celen, A. Selim, and S. Wongwises, "Experimental analysis of the single phase pressure drop characteristics of smooth and micro fin tubes," Int. Communications in Heat and Mass Transfer, vol. 46, pp. 58-66, 2013.

[3] M. Dastmalchi, A. Arefmanesh, and G. A. Sheikhzadeh, "Numerical investigation of heat transfer and pressure drop of heat transfer oil in smooth and micro- finned tubes," Int. J. of Thermal Sci., vol. 121, pp. 294-304, 2013.

[4] B. Kristiawan and S. Kamal, "ThermoHydraulic Characteristics of Anatase Titania Nanofluids Flowing Through a Circular Conduit," J. of Nanoscience and Nanotechnology, vol. 16, no. 6, pp. 60786085, 2016.

[5] G. Li, L. Huang, and L. Tao, "Experimental investigation of refrigerant condensation heat transfer characteristics in the horizontal microfin tubes," Applied Thermal Engineering, vol. 123, pp. 1484-1493, 2017.

[6] Z. Ma, A. Zhou, J. Zhang, and Y. Wang, 'Experimental investigation on the friction characteristics of water - ethylene glycol mixture flow in internal helical finned horizontal tubes," Experimental Thermal and Fluid Science, vol. 89, pp. 1-8, 2017.

[7] A. T. Wijayanta, T. Istanto, K. Kariya, and A. Miyara, "Heat transfer enhancement of internal flow by inserting punched delta winglet vortex generators with various attack angles," Experimental Thermal and Fluid Science, vol. 87, pp. 141-148, 2017.

[8] A. T. Wijayanta, I. Yaningsih, M. Aziz, and T. Miyazaki, "Double-sided delta-wing tape inserts to enhance convective heat transfer and fluid flow characteristics of a double-pipe heat exchanger," Applied Thermal Engineering, vol. 145, pp. 27-37, 2018.

[9] Z. Wu, Y. Wu, B. Sundén, and W. Li, "Convective vaporization in micro-fin tubes of different geometries," Experimental Thermal and Fluid Science, vol. 44, pp. 398-408, 2013.

[10] I. Yaningsih, A. Tri, T. Miyazaki, and S. Koyama, "International Journal of Thermal Sciences Thermal hydraulic characteristics of turbulent single-phase flow in an enhanced tube using louvered strip insert with various slant angles," Int. J. of Thermal Sci., vol. 134, pp. 355-362, 2018. 